\title{
Epidemiology and Outcomes of Hospitalized Burn Patients in Gaza Strip: A Descriptive Study
}

\author{
Aymen Elsous ${ }^{1}$, Mahmoud Ouda ${ }^{1}$, Samah Mohsen $^{1}$, Mohammed Al-Shaikh ${ }^{1}$, \\ Siham Mokayad ${ }^{1}$, Nafiz Abo-Shaban ${ }^{2}$, Abed Al-Rahman Hamad ${ }^{3}$
}

\begin{abstract}
BACKGROUNG: Burns are serious health problems and leading causes of mortality and morbidity in the Eastern Mediterranean Region. This study aimed to overview the epidemiological profile and to present outcomes among hospitalized burn patients in AL Alamy burn center in Gaza.

METHODS: This was a cross-sectional retrospective study of medical records of hospitalized patients from July 2013 to June 2014. Descriptive analysis for studied variables was applied and $P \leq 0.05$ considered statistically significant.

RESULTS: One humdred eighty nime admissions, $60.8 \%$ were males and $63 \%$ were under 10 years old. Burn patients in the age range between 19-40 years represented $25.9 \%$. Most common burn injuries were accidental (86.2\%), located at home (88.9\%), caused by scald (66.1\%) and by fire flame (23.8\%). On admission, the majority of cases presented with second degree burn (45.5\%) or mixed burn (38.6\%). The mean TBSA was 11.86 (SD \pm 10.78 ) ranging from $1 \%$ to $75 \%$ whereas, the mean hospital length of stay was 11.45 (SD \pm 12.60$)$ ranging from 1 to 115 days. Total in hospital mortality rate was $2.1 \%$ and length of stay was significantly associated with TBSA $(P<0.001)$.

CONCLUSION: Young children below 10 years seem to be at a higher risk for burn injuries. A significant improvement in burn patients care is observed and practiced and in hospital mortality rate is better compared to neighbouring countries. Preventive programs focusing on safety measures, especially for mothers working in the home, should be implemented urgently to save our children.

KEYWORDS: Burns, Hospitalized patients, Length of stay, Mortality
\end{abstract}

DOI: http://dx.doi.org/10.4314/ejhs.v26i1.4

\section{INTRODUCTION}

Burn injuries are unique traumas that are recognized as serious public health problems both in low and high income countries (1). They account for $1 \%$ of the global burden of diseases (2) and are ranked fourth among all injuries (3). They cause a significant level of morbidity and mortality and have a considerable physical, psychological and economic loss (4-6). The burn is not only fatal for patients themselves, but also poses burden to health system by taking up the available healthcare resources. Risk factors include low socioeconomic conditions, poor living conditions, illiteracy, overcrowding and floor level cooking (7-9). It is associated with long hospital stay and mortality $(10,11)$. Burns are classified according to type of injury. They are accident, self inflicted, scald, fire flame, immersion, explosive, electrical or inhalation, and the rate of occurrence varies globally (12-14). Mortality from burns is mainly caused by infection. It is estimated that $75 \%$ of all deaths related to burn are caused by $\mathrm{P}$. aeroginosa, S. aureus, Klebsiella spp, Acinetobacter spp, and Candida (15-18). Burn injuries in Eastern Mediterranean Region (EMR), which comprises 22 countries from Morocco to

\footnotetext{
${ }^{1}$ Quality Improvement and Infection Control Office. Shifa Medical Complex, Gaza Strip, Palestine ${ }^{2}$ Department of Plastic Surgery, Al Alamy Burn Center, Shifa Medical Complex, Gaza Strip, Palestine ${ }^{3}$ Department of Applied Medical Technology, Al Aqsa University, Gaza Strip, Palestine Corresponding Author: Aymen Elsous, Email: aymenelsous65@gmail.com
} 
Afghanistan including Palestine, is a major public health problem. According to the World Health Organization (WHO) (19), the overall incidence of burn globally and within EMR was estimated to be 110 and 187 per 100.000 respectively.

To our knowledge, there is lack of information on the characteristics of burn injuryrelated patients admitted to burn units in Gaza, or even on the quality of care and performance of burn units. Such information is useful for setting preventive measures and helping policy makers to cope with underlying risk factors.

The aim of this study was to describe the charachteristics and outcomes of patients admitted to Al Alamy Burn Center at Shifa Medical Complex in order to give recommendations regarding their prevention and present outcomes indicators in regard to length of hospital stay and mortality rate.

\section{MATERIALS AND METHODS}

Study setting: The study took place at Al Alamy Burn Center which had been established in 2007 and is located in Shifa Medical Complex in Gaza Strip. It serves more than 1.1 million inhabitants and covers all Gaza governorates except south governorates. It has 12 beds distributed in 6 rooms in addition to a dressing and hydrotherapy room. Furthermore, three ICU beds and one operating room are available in service. Care is provided by plastic surgeons, nurses and physiotherapists besides psychological support from psychologists.

Study design and sample: This was a retrospective review of medical records for burns patient admitted to Al Alamy Burn center over one year. Data was extracted from admission and assessment sheets, adopted from WHO, written by plastic surgeons and signed by head of department. It includes but not limited to sociodemographic variables, type of burn injury, total body surface area (TBSA), burn degree, discharge status and length of hospital stay. TBSA was estimated by plastic surgeons using the Rule of Nine (20). All age group patients admitted to $\mathrm{Al}$ Alamy Burn Center at Shifa Medical Complex, from July, 2013 to June, 2014, and spent at least one night and had complete admission and assessment sheet were included. A total of 204 admissions were registered. Only acute burn patients were included. Therefore, the 15 patients admitted for reconstruction purposes were excluded. Thus, the remaining 189 registered files constituted the study sample.

Statistical analysis: Age, gender, location of injury, TBSA, length of hospital stay and clinical outcome including mortality were the study variables. Data input, analysis and tabulation were done using SPSS for windows version 20. Chisquared test and t-test were used where applicable to determine statistical differences, and $P$-value $\leq$ 0.05 was considered statistically significant.

Ethical consideration: This study was approved by committee members of the Institutional Review Board of Shifa Medical Complex.

\section{RESULTS}

The distribution of patients according to age, gender, cause of burn, site of injury and other variables are presented in Table 1 . The patients included 115 males $(60.8 \%)$ and 74 female (39.2\%). The male-female ratio of all burns injuries was 1.5:1. Age was not normally distributed and ranged from 1 month to 65 years (mean $12.58 \pm$ SD14.05; median 5,00 SE 1.02). Almost $88.9 \%$ of the burns occurred at home, and $86.2 \%$ of them resulted from accidents. The inhospital and under 10 years mortality rate were $2.1 \%$ and $1.6 \%$ respectively.

Age group exposure: The majority of burns occurred among less than 10 years old children followed by adults from the $19-40$ age group (63\% and $25.9 \%$ respectively) (Figure 1).

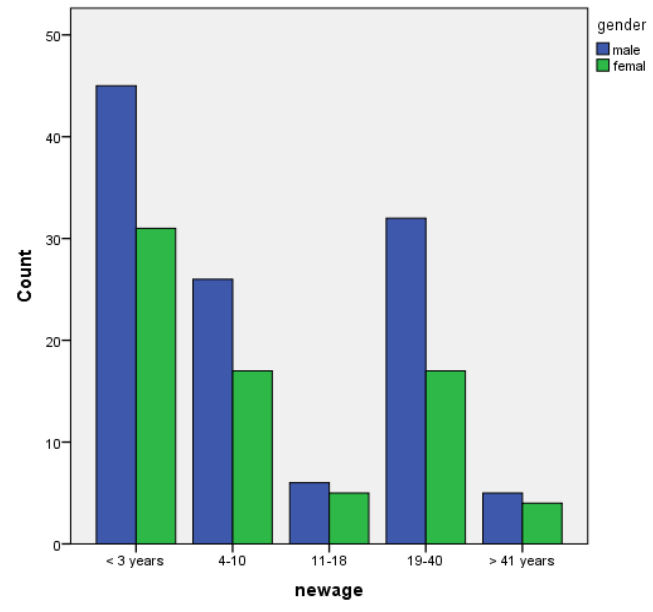

Figure 1: Incidence of burn among age group 
Table 1: Baseline characteristics of burn patients

\begin{tabular}{|c|c|c|}
\hline variables & $\mathrm{N}^{\mathrm{a}}$ & $\%$ \\
\hline Gender & & \\
\hline male & 115 & 60.8 \\
\hline female & 74 & 39.2 \\
\hline Age in years & & \\
\hline$\leq 3 \mathrm{y}$ & 76 & 40.2 \\
\hline $4-10$ & 43 & 22.8 \\
\hline $11-18$ & 11 & 5.8 \\
\hline $19-40$ & 49 & 25.9 \\
\hline$>40 y$ & 9 & 4.8 \\
\hline \multicolumn{3}{|l|}{ TBSA } \\
\hline$\leq 10$ & 121 & 64.0 \\
\hline $11-30$ & 56 & 29.6 \\
\hline $31-50$ & 11 & 5.8 \\
\hline$>50$ & 1 & 0.5 \\
\hline \multicolumn{3}{|l|}{ Address } \\
\hline north & 48 & 25.4 \\
\hline gaza & 107 & 56.6 \\
\hline middle area & 28 & 14.8 \\
\hline south & 4 & 2.1 \\
\hline \multicolumn{3}{|l|}{ Gaz cylinder } \\
\hline not available & 38 & 20.1 \\
\hline inside home & 122 & 64.6 \\
\hline outside home & 9 & 4.8 \\
\hline \multicolumn{3}{|l|}{ Electricity generator } \\
\hline not available & 64 & 33.9 \\
\hline inside home & 22 & 11.6 \\
\hline outside home & 26 & 13.8 \\
\hline \multicolumn{3}{|l|}{ Etiology of burn } \\
\hline scald & 125 & 66.1 \\
\hline Fire flame & 45 & 23.8 \\
\hline others & 18 & 9.5 \\
\hline \multicolumn{3}{|l|}{ Circumstances } \\
\hline accident & 163 & 86.2 \\
\hline work related & 4 & 2.1 \\
\hline \multicolumn{3}{|l|}{ location of injury } \\
\hline home & 168 & 88.9 \\
\hline work & 8 & 4.2 \\
\hline other buildings & 4 & 2.1 \\
\hline street & 6 & 3.2 \\
\hline \multicolumn{3}{|l|}{ Burn degree } \\
\hline first & 3 & 1.6 \\
\hline second & 86 & 45.5 \\
\hline deep second & 17 & 9.0 \\
\hline third & 9 & 4.8 \\
\hline $\operatorname{mix}$ & 73 & 38.6 \\
\hline \multicolumn{3}{|l|}{ Surgical procedure } \\
\hline debridement & 35 & 18.5 \\
\hline scaratomy- fascotomoy & 1 & 0.5 \\
\hline graft & 13 & 6.9 \\
\hline dressing & 140 & 74.1 \\
\hline
\end{tabular}

$\mathrm{N}^{\mathrm{a}}=189$, otherwise indicated
Place of injury: The commonest place of burn injuries was the home. Almost eighty nine percent of burns were home encountered, in which $77.8 \%$ happened indoors, and the rest occurred outdoors. Neither the place of injury nor the site of injury were significantly associated with etiology of injury $(P=.0189, P=0.168$ respectively $)$.

Etiology of injury: The commonest cause of burn injuries was scalding followed by fire flame. Scalding and fire flame represented $66.2 \%$ and $23.8 \%$ respectively. The remained $9.5 \%$ burns were caused either by chemical, immersion, electrical or explosion. Children below 3 years old and school children in the age group between 4 to 10 were the most affected, and burn injurie were caused mainly by scalding, but fire flame was mostly common among group aged 19-40 years (Figure 2).

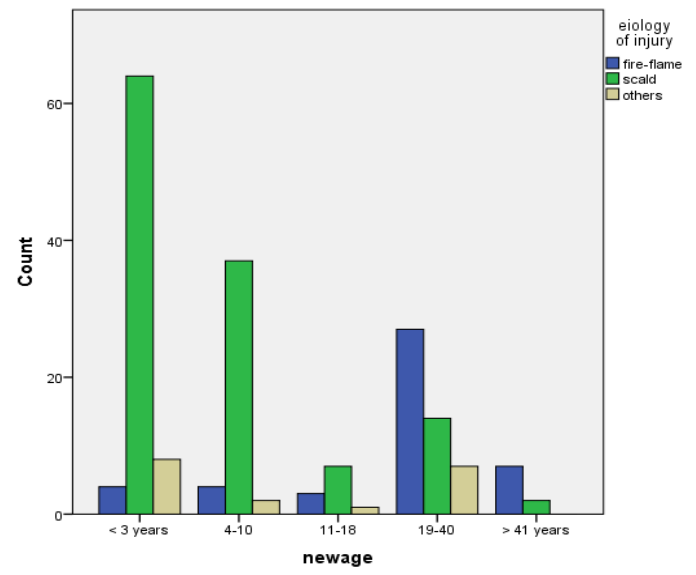

Figure 2: Distribution of etiology of burn injuries by age group

Admission: From July 2013 to June 2014, 204 patients were admitted to Al Alamy Burn Center, but only 189 cases were included in the study. The remaining 15 cases were excluded because they did not meet the criteria and were admitted for reconstruction purpose. Seventy three percent of them were acute injuries directly admitted from the hospital emergency department, whereas 23.3\% were acute cases referred from other hospitals. The admitted cases were from three governorates within a coverage zone of Al Alamy Burn Center. They were 48 (25.4\%), 107 (56.6\%) and 28 (14.8\%) from North, Gaza City, and Middle Zone respectively. The remained 4 (2.1\%) patients were from south governorate usually 
covered by a burn unit at Nasser Medical Complex.

Extent and degree of burn: The vast majority of patients $(64 \%)$ sustained burns of $10 \%$ or less. 56 patient $(29.6 \%)$ sustained burn between $11-30 \%$. Moreover, $11(5.8 \%)$ and one patient $(0.5 \%)$ sustained burn between $31-50 \%$ and above $50 \%$ respectively (Figure 3 ). Three patients (1.6\%) had first degree burns, 17 (9\%) and 9 (4.8\%) patients had deep second and third degree burn respectively. In adition, $73(38.6 \%)$ patients presented with mix burns degree.

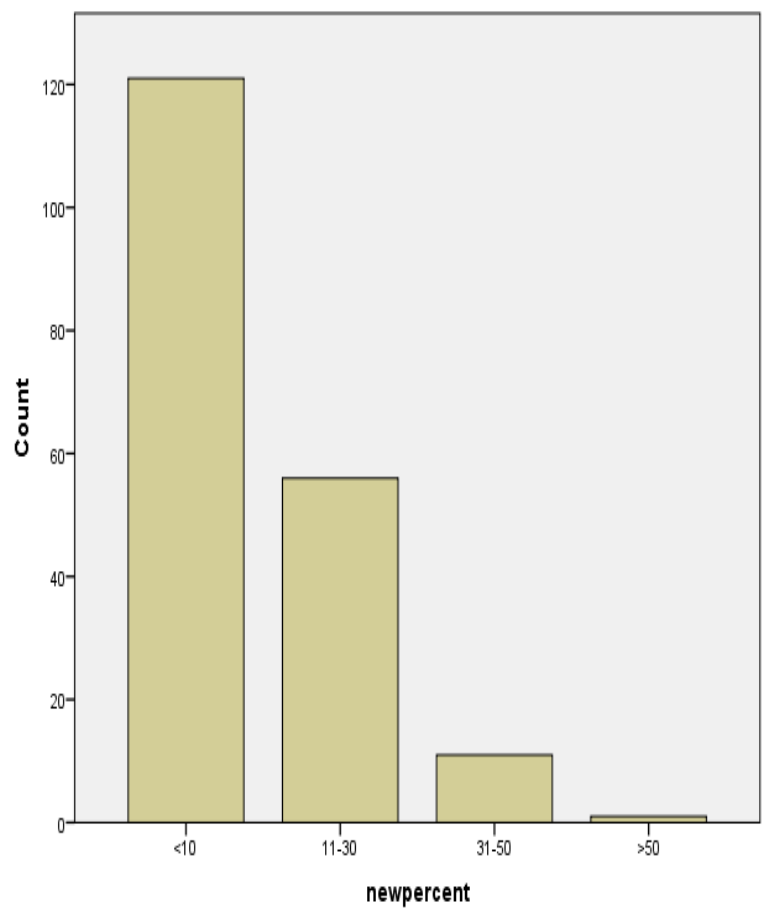

Figure 3: Frequency of extent of burn among hospitalized burns patients

Length of hospital stay: The length of hospital stay was not normally distributed and ranged from 1 day to 115 days (mean: $11.45 \mathrm{SD} \pm$ 12.60; median: 8.00 SE. 0.96). There was no statistical differences between length of hospital stay and gender (t-test $=0.846, P=0.400)$ and between length of hospital stay and etiology of injury $(\mathrm{F}=$ $0.480, P=0.619)$. There was no significant correlation between age and hospital stay $(P=$ 0.737 ), but a statistical significance between length of hospital stay $(11.45 \pm 12.60)$ and TBSA $(11.86 \pm 10.78)$ was observed $(\mathrm{F}=3.902, P=$ 0.022). Patients who had TBSA greater than $30 \%$ had longer hospital stay than those who had $30 \%$ TBSA or less $(\mathrm{F}=13.489, P=0.000$, median days: 9.00) (Figure 4). Only one patient had TBSA of $75 \%$ spent 8 days in hospital then died. Approximately Sixty eight percent of cases required less than 15 days stay in hospital. Thirtytwo (16.9\%) stayed between 15 - 30 days and ten patients $(5.1 \%)$ required more than a month in hospital (Table 2).

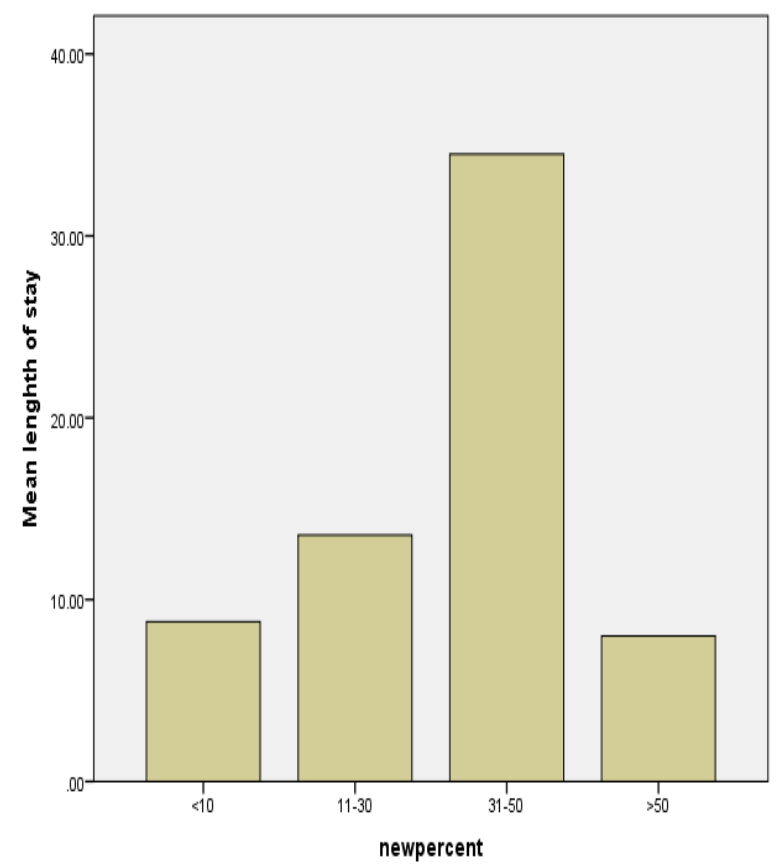

Figure 4: Length of hospital stay in regard with TBSA 
Table 2: Duration of hospital length of stay in weeks relative to TBSA

Hospital length of stay / weeks

\begin{tabular}{lllllllll} 
TBSA \% & $\mathbf{1}$ & $\mathbf{2}$ & $\mathbf{3}$ & $\mathbf{4}$ & $\mathbf{5}$ & $\mathbf{6}$ & $\mathbf{7}$ & $\boldsymbol{8}$ \\
$\leq 10$ & 71 & 22 & 4 & 7 & 3 & 1 & 0 & 1 \\
$11-30$ & 21 & 21 & 14 & 0 & 5 & 0 & 1 & 0 \\
$31-50$ & 1 & 1 & 3 & 0 & 0 & 1 & 0 & 2 \\
$>50$ & 0 & 1 & 0 & 0 & 0 & 0 & 0 & 0 \\
\hline
\end{tabular}

Mortality: Of the 189 admissions, 4 patients died in hospital, showing in-hospital mortality rate of $2.1 \%$. Out of 4 patients, 3 died of direct cause from fire flame, and their TBSA ranged from 30$75 \%$ (mean TBSA: $47,5 \%$ ). They were two adults from the 19-40 age group; one was more than 40 years while one was below 3 years. Two of them had second degree burn, while the remaining had mix burn degree (usually deep second or second with third degree). The mortality rate was $0.56 \%$ when TBSA was $\leq 30 \%, 18 \%$ when TBSA was between $31 \%-50 \%$ and $100 \%$ when TBSA was over $50 \%$ ( $\mathrm{P}<0.01$ ), showing that only 1 patient lies above $50 \%$ TBSA group and had $75 \%$.

\section{DISCUSSION}

Burns are among the most serious and significant health problems worldwide and cause considerable physical, psychological and economical losses. Epidemiological studies are a prerequisite for effective prevention programs as each population has its own epidemiological characteristics. This study is unique and is the first study performed that provides important information about the epidemiological characteristics of burns injuries admitted to $\mathrm{Al}$ Alamy Burn Center. Moreover, it presents most important quality indicators of the center's performance in terms of length of hospital stay and in hospital mortality rate.

We analyzed 189 completed medical files retrospectively. Within the studied year, scalding was the most common cause of burn injuries, affecting mainly school and preschool age children. Moreover, open fire was common among adults. This observation is not new but consistent with other published reports (20-24).
Usually length of hospitalization and mortality are used for describing the outcome. mortality rate reflects the level of clinical care and burn severity. We reported a total in hospital mortality rate of $2.1 \%$ (4/189), while the under 3 years, 10 years and 19 years, between $19-40$ years and above 40 years in-hospital mortality rates were $1.3 \%, 1.6 \%, 1.5 \%, 4 \%$, and $0 \%$ respectively. Similar hospital based studies conducted in Eastern Mediteranean Region (EMR) showed higher in hospital mortaliy rate compared to our findings: $5 \%$ in Morocco (25), 9.4\% in Saudi Arabia (26), 3\% in United Arab of Emirates (23), $5.3 \%$ in Kuwait (27), $16 \%$ in Afghanistan (28), Iran (13), and 3.2\% in "Israel" $(22,29)$. In Taiwan and Hong Kong, the overall mortality rate were $3.7 \%$ (30) and $2.3 \%$ (31) respectively. The mortality rate in our study is quite similar to other reports (32). Under 10 year mortality rate was quite close to some reports from Kuwait (1.3\%) (33) and Saudi Arabia (1.0\%) (34), but too much better than the one reported from Iran (6.4\%) (35, $36)$ and India (60.8\%) (37).

We found the mean length of hospital stay to be 11.45 days. Length of hospital stay was significantly associated with the extent of burns or burn thickness. It is worth saying that length of hospital stay was shorter when TBSA increased beyond $50 \%$ due to high mortality rate in this group, which is consistent with other studies (3741). Patients who had TBSA greater than $30 \%$ had longer hospital stay than those who had 30\% TBSA or less (42). More than half of the patients spent less than 14 days in hospital which is quite similar and consistent to Ali's study (32).

This study has some limitations. First, it is a retrospective study and therefore is subject to all problems related to the type of this study. Second, 
in this study, we have not presented the different types of treatments and interventions provided to burn patients, which have direct influence on the rate of mortality and their length of hospital stay.

In conclusion, burn injuries are important public health issues worldwide. However, most of them are preventable. Since most burn injuries are domestic, preventive and educational programs should be set focusing on mothers and housewives to emphasize the importance of safety and carefulness. Healthcare workers were able to overcome difficulties and problems faced the healthcare system because of strict blockade imposed since 2007 by Israeli military. The results showed better outcomes interms of mortality and length of hospital stay compare to countries which share similar demographic and economic profiles. Length of hospital stay has linear relationship with TBSA which reflects burn unit's performance and commitment to burn theories: 1\% TBSA burn requires 1 day in hospital care. This shows high quality and standardizes care provided to our patients. This finding could be attributed to early surgical intervention and skin grafting, modern topical and systemic antibiotics, nursing care. Furthermore, immediate fluid and electrolyte replacement, nutritional support and adherence to infection prevention and standard precautions.

\section{ACKNOWLEGMENTS}

The authors would like to thank Al Alamy Burn Center staff for their support and work facilitation. Acknowledgments are also due to various colleagues for their valuable comments.

\section{REFERENCES}

1. Jayaraman V, Ramakrishnan KM, Davies MR. Burns in Madras, India: an analysis of 1368 patients in 1 year. Burns, 1993;19(4):339-344.

2. Leistikow BN, Martin DC, Milano CE. Fire injuries, disasters and costs from cigarettes lights, a global overview. Prev Med, 2000;31(2 Pt 1):91-99.

3. Peck MD. Epidemiology of burns throughout the world. Part I: distribution and risk factors. Burns, 2011;37(7):1087-1100.

4. Barret JP, Gomez P, Solano I, GonzalezDorrego M, Crisol FJ. Epidemiology and mortality of adult burns in Catalonia. Burns, 1999;25(4):325-329.

5. Groohi B, Alaghehbandan R, Rastegar L. Analysis of 1089 burn patients in a province of Kurdistan, Iran. Burns, 2002;28(6):569574.

6. Mohammadi AA, Amini M, Mehrabani D, Kiani Z, Seddigh A. A survey on 30 months electrical burns in Shiraz University of Medical Sciences Burn Hospital. Burns, 2008;34(1):111-113.

7. Zeitlin R. Late outcome of paediatric burns scarred for life. Ann Chir Gynaecol, 1998;87(1):80.

8. Zeitlin RE, Jarnberg J, Somppi EJ, Sundell B. Long-term functional sequelae after paediatric burns. Burns, 1998;24(1):3-6.

9. Zeitlin RE. Long-term psychosocial sequelae of paediatric burns. Burns, 1997;23(6):467472.

10. Nigro MV, Freitas ET, Lopes Junior SC, Dalcumune F, Bueno Netto RF, Sanches ME. Perfil epidemiológico das crianças internadas por queimadura no Hospital Universitário Evangélico de Curitiba (HUEC) no período de julho de 2007 a fevereiro de 2008. Arq Catar Med, 2009;38:172-174.

11. Fernandes FM, Torquato IM, Dantas MA, Pontes Júnior FA, Ferreira JA, Collet N. Burn injuries in children and adolescents: clinical and epidemiological Characterization. Rev Gaucha Enferm, 2012;33(4):133-141.

12. World Health Organization Health Statistics and Health Information Systems. Cause specific mortality: World Bank income groups estimates for 2008. Geneva [CH]: World Health Organization; 2008, [http://www.who.int/healthinfo/global_burden _disease/estimates_regional/en/index.html] Accessed February 2015

13. Saadat M. Epidemiology and mortality of hospitalized burn patients in Kohkiluye va Boyerahmad province (Iran): 2002-2004. Burns, 2005;31(3):306-309.

14. Iqbal T, Saaiq M. Epidemiology and outcome of burns: Early experience at the country's first national burns center. Burns, 2013;39(2):358-362.

15. Rastegar A, Alaghehbandan R, Akhlaghi L. Burn wound infections and antimicrobial resistance in Tehran, Iran: an increasing 
problem. Ann Burns Fire Disasters, 2005;18(2):68-73.

16. Oncul O, Ulkur E, Acar A, Turhan V, Yeniz E, Karacaer Z, Yildiz F. Prospective analysis of nosocomial infections in a burn care unit, Turkey. Indian J Med Res, 2009;130(6):758764.

17. Mehta M, Dutta P, Gupta V. Bacterial isolates from burn wound infections and their antibiograms: A eight-year study. Indian $J$ Plast Surg, 2007;40:25-28.

18. Rezaei E, Safari H, Naderinasab M, Aliakbarian H. Common pathogens in burn wound and changes in their drug sensitivity. Burns, 2011;37(5):805-807.

19. Annual incidence for selected causes, in WHO Regions, estimates for 2004. [http://www.who.int/healthinfo/global_burden _disease/estimates_regional/en/index.html] Accessed February 2015.

20. Warden GD, Heimbach DM. Burns. In: Schwartz SI, Shires GT, Spencer FC, eds. Principles of surgery. 7th ed. New York, McGraw-Hill; 1999:223-262.

21. Alsalman AK, Algadiem EA, Alalwan MA, Farag TS. Epidemiology of infant burn in Eastern Saudi Arabia. Saudi Med J, 2015;36(3):324-327.

22. Gurfinkel R, Cohen AD, Glezinger R, Krieger Y, Yancolevich N, Rosenberg L. Burns at the Soroka university medical center- a two years experience. Ann Burn Fire Disasters, 2007;20(1):3-6.

23. Grivna M, Eid HO, Abu-Zidan FM. Epidemiology of burns in the United Arab Emirates: Lessons for prevention. Burns, 2014;40(3):500-505.

24. Morad M, Hemmo-Lotem M, Kandel I, Hyam E, Merrick J. Burn injuries and adolescents in Israel. Int $J$ Adolesc Med Health, 2004;16(3):201-205.

25. Elkafssaoui S, Tourabi K, Bouaiti E, Ababou K, Moussaoui A, Ennouhi MA, Boulmaarouf A, Mrabet M, Quyou A, Soulaymani A, Ihrai H. Epidemiological analysis of burn patients in the military hospital, Rabat, Morocco. Ann Burns Fire Disasters, 2011;24(3):115-119.

26. Jamal YS, Ardawi MS, Ashy AA, Merdad H, Shaik SA. Burn injuries in the Jeddah area of
Saudi Arabia: a study of 319 cases. Burns, 1989;15(5):295-298.

27. Sharma PN, Bang RL, Ghoneim IE, Bang S, Sharma P, Ebrahim MK. Predicting factors influencing the fatal outcome of burns in Kuwait. Burns, 2005;31(2):188-192.

28. Calder F. Four years of burn injuries in a Red Cross hospital in Afghanistan. Burns, 2002;28(6):563-568.

29. Yanculovich N, Perry ZH, Gurfinkel R, Rosenberg L. Objective Estimates of the Risk Factors for Death and Length of Hospitalization following Burn Injuries, Soroka University Medical Center, 20012002. IMAJ, 2013;15(4):152-154.

30. Chien WC, Pai L, Lin CC, Chen HC. Epidemiology of hospitalized burns patients in Taiwan. Burns, 2003; 29(6):582-588.

31. Ho W, Ying S. An epidemiological study of 1063 hospitalized burn patients in tertiary burns centre in Hong Kong. Burns, 2001;27(2):119-123.

32. Ali MH. Patient of burn injuries at King Fahad hospital, Al Baha: a study of 277 cases. Ann Saudi Med, 1997;17(1):104-107.

33. Othman N, Kendrick D. Epidemiology of burn injuries in the East Mediterranean Region: a systematic review. BMC Public Health, 2010;10:83.

34. Sharma PN, Bang RL, Al-Fadhli AN, Sharma $\mathrm{P}$, Bang S, Ghoneim IE. Paediatric burns in Kuwait: incidence, causes and mortality. Burns, 2006;32(1):104-111.

35. Maghsoudi H, Samnia N. Etiology and outcome of pediatric burns in Tabriz, Iran. Burns, 2005;31(6):721-725.

36. Alaghehbandan R, MacKay Rossignol A, Rastegar Lari A. Pediatric burn injuries in Tehran, Iran. Burns, 2001;27(2):115-118.

37. Ganesamoni S, Kate V, Sadasivan J. Epidemiology of hospitalized burn patients in a tertiary care hospital in South India. Burns, 2010;36(3):422-429.

38. Ortiz-Prado E, Armijos L, Iturralde AL. A population-based study of the epidemiology of acute adult burns in Ecuador from 2005 to 2014. Burns, 2014; 41(3):582-589

39. Burton KR, Sharma VK, Harrop R, Lindsay R. A population-based study of the epidemiology of acute adult burn injuries in the Calgary Health Region and factors 
associated with mortality and hospital length of stay from 1995 to 2004. Burns, 2009;35(4):572-579.

40. Onarheim H, Guttormsen A, Eriksen E. Burns treated at the Haukeland University Hospital Burn Centre-20 years of experience. Tidsskr Nor Laegeforen, 2008; 128(10):1168-1171.

41. Haik J, Liran A, Tessone A, Givon A, Orenstein A, Peleg K. Burns in Israel: demographic, etiologic and clinical trends, 1997-2003. IMAJ, 2007; 9(9): 659-662.

42. Johnson LS, Shupp JW, Pavlovich AR, Pezzullo JC, Jeng JC, Jordan MH. Hospital length of stay--does $1 \%$ TBSA really equal 1 day?. J Burn Care Res, 2011;32(1):13-19. 